First publ. in: Zoology 109 (2006), 4, pp. 261-276

\title{
Natural hybridization in primates: One evolutionary mechanism
}

\author{
Michael L. Arnold ${ }^{\mathrm{a}, *}$, Axel Meyer ${ }^{\mathrm{b}}$ \\ a Department of Genetics, Life Sciences Building, University of Georgia, Athens, GA 30602, USA \\ ${ }^{\mathrm{b}}$ Lehrstuhl für Zoologie und Evolutions Biologie, Department of Biology, University of Konstanz, D-78457 Konstanz, Germany
}

Received 9 November 2005; received in revised form 6 March 2006; accepted 15 March 2006

\begin{abstract}
The role and importance of natural hybridization in the evolutionary histories of animal taxa is still debated. This results largely from a history of zoological investigations that assumed, rather than documented, a limited evolutionary role for this process. However, it is now becoming apparent that, just as for plants, the creative effects of reticulate evolution are widespread in animal taxa as well. This conclusion is supported by the documentation of numerous instances of the formation of new taxa and the genetic enrichment through introgressive hybridization. In the present review, we use primates as a paradigm for how natural hybridization can affect the evolution of species complexes and remains a footprint on genomes. Findings for a number of groups, including basal (e.g. lemurs) and derived (e.g. Old World apes) lineages, demonstrate that introgression and hybrid speciation have caused a reticulate pattern that is still detectable in the, often mosaic, genomes of primates. For example, results from genetic analyses of our own species demonstrate the process of past introgressive hybridization with the progenitors of our sister taxa (i.e. chimpanzees and gorillas) and most likely also our extinct, close relatives in the hominid lineage.
\end{abstract}

Keywords: Primates; Introgression; Hybridization; Reticulation; Web of life

\section{Introduction}

Pure species have of course their organs of reproduction in a perfect condition, yet when intercrossed they produce either few or no offspring. Hybrids, on the other hand, have their reproductive organs functionally impotent ... (Darwin, 1859).

The majority of ... hybrids are totally sterile ... those hybrids that produce normal gametes ... are ... unsuccessful in most cases ... Finally, when they do backcross to the parental species, they normally produce genotypes of inferior viability ... Successful

\footnotetext{
${ }^{*}$ Corresponding author.

E-mail address: arnold@plantbio.uga.edu (M.L. Arnold).
}

hybridization is indeed a rare phenomenon among animals (Mayr, 1963).

Botanists recognize the importance of introgressive hybridization in evolution. Our results ... indicate that zoologists must do the same (Dowling and DeMarais, 1993).

The role of natural hybridization (i.e. "successful matings in nature between individuals from two populations, or groups of populations, that are distinguishable on the basis of one or more heritable characters"; Arnold (1997) as adapted from Harrison (1990)) in the evolutionary history of numerous species is now well recognized (e.g. see Arnold, 1997, 2004b, 2006; Seehausen, 2004; Mallet, 2005). Possible outcomes from such genetic exchange include (i) the amalgama- 
tion of the hybridizing lineages, (ii) the reinforcement of reproductive barriers, (iii) the derivation of new, hybrid, lineages (e.g. "hybrid speciation") and/or (iv) the transfer of genes underlying adaptive traits thus allowing the introgressed form to establish in novel habitats (see Arnold, 2006 for a review).

The impact of introgressive hybridization and hybrid speciation has been documented for many plant assemblages. Though some reviews have also emphasized the importance of reticulate evolution in animal taxa (e.g. Dowling and DeMarais, 1993; Arnold, 1997, 2004a, 2006; Grant and Grant, 2002; Seehausen, 2004; Mallet, 2005), there remains a level of skepticism among zoologists concerning the prevalence, and importance in evolution that this process plays. This results from an assumption rooted in the formulation of not only NeoDarwinism, but in Darwinism itself. In order to illustrate the process of divergent evolution, Darwin (1859) logically attached great significance to the decreased fertility and viability of many natural and artificial hybrids. An emphasis on the lowered fitness of many hybrids, as a litmus test of the process of "Biological Speciation", was also a major theme in the writings of Neo-Darwinists such as Dobzhansky (1937) and Mayr (1942, 1963). What was ignored, or argued against - at least for animal taxa — was the possibility that natural hybridization could form novel, fit genotypes and, sometimes, new taxa (see Arnold, 1997 for a discussion). As an example, Fig. 1 illustrates the consequences of a speciation event in African cichlids resulting from introgressive hybridization. This conclusion was drawn from the incongruence between the taxonomy and the phylogenetic tree constructed from mitochondrial sequences (Salzburger et al., 2002). Such incongruence between taxonomy and phylogenies, or between phylogenies based on different data sets, is often both the first hint and an evidential footprint of past reticulate events that led to mosaic genomes. We will repeatedly refer to these types of findings that have increased in frequency in recent years due to the widespread use of DNA markers to infer phylogenetic relationships. Moreover, an increased use of several unlinked genetic markers for phylogenetic purposes led, at least in some instances, to the inference that not all genetic and organismal lineages experienced the same evolutionary history, as might have been expected if no hybridization had occurred. However, these data reflect only a snapshot of the evolutionary process and as such must be considered in the light of other findings, including ancient and current species distributions, behavior that affects the potential for hybridization and introgression, etc.

It is important to state at the outset that we recognize the potentially important role that processes such as incomplete lineage sorting and convergent evolution may also play in the genetic structuring of contemporary

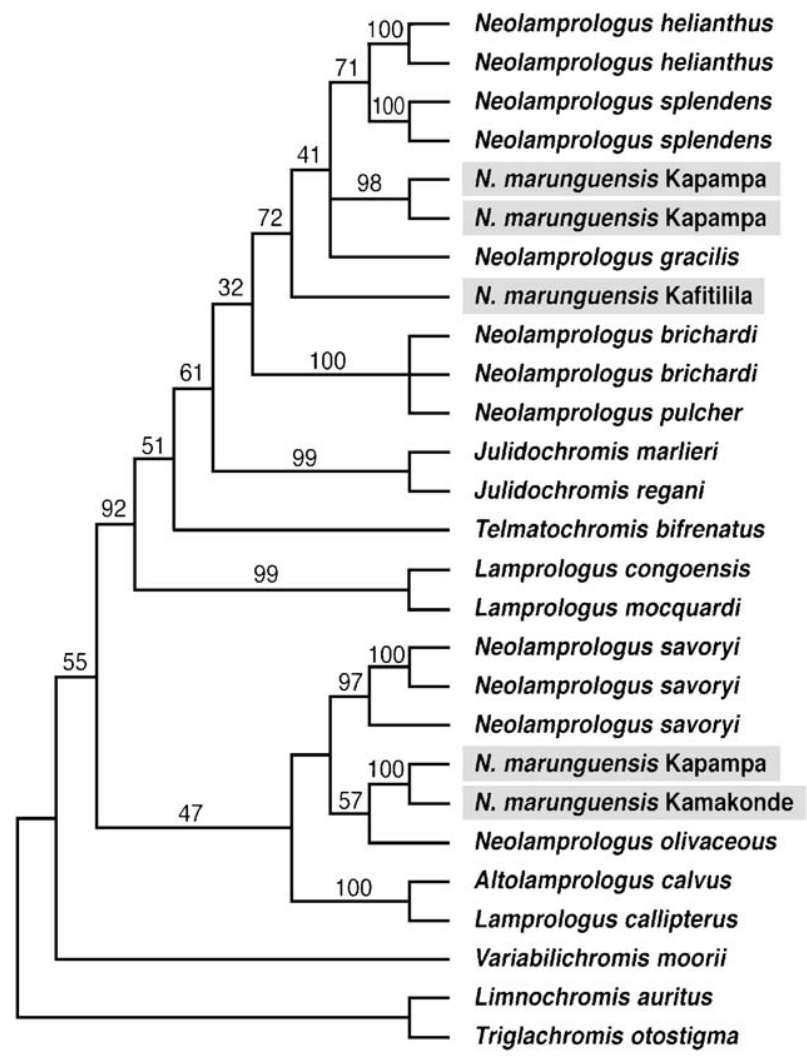

Fig. 1. Parsimony tree for lamprologine cichlids derived from mtDNA control region and cytochrome oxidase b sequence data. Note the paraphyletic distribution of haplotypes identified for Neolamprologus marunguensis, indicated by bold type shading (from Salzburger et al., 2002).

populations (see Avise (1994, 2000) for excellent descriptions of the processes that can contribute to homoplasy in phylogenetic analyses). Indeed, these are often the alternative explanation for patterns that suggest reticulations. However, in this review we will emphasize why primates are an excellent assemblage in which to exemplify the potential for creative genetic and evolutionary effects resulting from gene exchange among animal lineages. In particular, we will demonstrate the effect of natural hybridization and introgression on the genetic makeup and evolutionary trajectories of primates from both the Old and New Worlds. Our discussion will follow a phylogenetic scheme. First, we will consider New World primates belonging to two different assemblages: (i) atelids (howler monkeys) and (ii) callitrichids (marmosets and tamarins). We will then discuss findings for a series of Old World primate species complexes: (i) prosimians (lemurs), (ii) colobines (langurs), (iii) cercopithecines (mangabeys, baboons, macaques) and (iv) hominoids (family Hylobatidae - gibbons; family Hominoidae - orangutans, gorillas, chimpanzees, bonobos and humans). In considering the clade containing our own species, we will examine how gene exchange has impacted the sister taxa of Homo, and the Homo 
lineage as well. We will argue that the pattern of DNA sequence variation sometimes used to support the conclusion of extensive incomplete lineage sorting within and among chimpanzees, bonobos, gorillas and humans is likely instead to be the result of introgression. Finally, we will propose "future directions" for research into primate evolution (and animal taxa in general) that facilitate (i) the recognition of reticulations and (ii) the investigation of the diverse, and fundamentally important, outcomes that may result from reticulate evolution.

\section{New world primates}

\section{Cebids (spider monkeys)}

"The phylogenetic relationships of similar haplotypes do not match their geographic distribution ... significant gene flow must have occurred at some time in the past to link such geographically separate haplotypes ..." (Collins and Dubach, 2000). This conclusion was drawn for spider monkey taxa and reflected the process of introgressive hybridization resulting in inferences of a web-like phylogenetic tree (Arnold, 1997). Reticulate evolution in this and other primate species complexes follows a pattern common in all instances where introgression is detected.

The above pattern is one of a semi-permeable boundary between the hybridizing forms (Key, 1968; Harrison, 1986; Navarro and Barton, 2003). The semipermeable nature of genomes is reflected by the discordant phylogenetic and geographic patterns among the various molecular markers (e.g. mtDNA, autosomal, $\mathrm{X}$ and $\mathrm{Y}$ chromosome-specific markers). As Key (1968) argued when applying the term "semi-permeable" to hybridizing taxa, different portions of the genome are expected to introgress at varying rates due to the action of selection, drift, etc., resulting in mosaic hybrid genomes constituted with markers from both taxa. When analyses involve sampling different portions of the genomes of related taxa it is likely that loci will be chosen that differ in their patterns of introgression and thus resolve discordant phylogenies. This is the case for many of the primate groups discussed in this review and indeed is clearly the case for the spider monkey complex (Collins and Dubach, 2000, 2001). We will argue that the comparison of multiple data sets and the pattern of contemporary hybridization in numerous primate taxa indicate the pervasive effect of introgression. However, we also recognize (and indicate where this is the case in the following examples) that sometimes other workers infer incomplete lineage sorting as the cause of discordances.

\section{Atelids (howler monkeys)}

Working against the hypothesis of parapatric speciation are the following observations: (1) A. palliata and A. pigra form mixed troops of howlers ... and sometimes interbreed suggesting that the contact zone may be secondary ... (Cortés-Ortiz et al., 2003).

Howler monkeys of the genus Alouatta are distributed throughout Meso- and South America. Up to 10 species and 19 subspecies are recognized throughout this range. Phylogenetic trees based on mitochondrial sequence data (1-4 individuals per species sampled) from the ATP synthase genes 6 and 8 as well as the cytochrome $b$ gene revealed reciprocal monophyly for the species from each of the two major geographic subdivisions (Cortés-Ortiz et al., 2003). Indeed, calculations based upon the mtDNA data suggested that these two clades diverged from a common ancestor 6.6-6.8 million years ago (mya). However, as in other groups of primates (see below) presumed ancient and contemporary areas of overlap and gene exchange have evidently occurred in the howler monkey assemblage resulting in phylogenies typified by paraphyly and polyphyly.

One present-day howler monkey hybrid zone between A. palliata and A. pigra occurs in an area of overlap in the Yucatan peninsula (Cortés-Ortiz et al., 2003). Though an alternate explanation for the variation present in this region is parapatric divergence into two new forms (i.e. A. palliata and A. pigra), Cortés-Ortiz et al. (2003) argued that the formation of mixed troops and obvious hybridization supported an hypothesis of secondary rather than primary intergradation.

In addition to the evidence for present-day gene exchange, gene trees based upon mitochondrial and nuclear sequences demonstrate the para- and polyphyly expected if past exchange led to the introgression of portions of the nuclear genome, or the entire mitochondrial genome, between various subspecies and species (Cortés-Ortiz et al., 2003). For example, a phylogeny constructed from mitochondrial gene sequence data detected a paraphyletic association involving the geographically widespread $A$. palliata and the restricted $A$. coibensis (Cortés-Ortiz et al., 2003). The presence of hybrid zones and the footprint of paraphyly in gene trees most likely reflect the role of reticulate evolution in this species complex.

\section{Callitrichids (marmosets and tamarins)}

"Morphological species that did not form monophyletic groups included Callithrix mauesi, C. penicillata, and $C$. kuhli ... In contrast to the confused picture regarding the $C$. penicillata, $C$. kuhli, $C$. jacchus group, C. geoffroyi [individuals] form a very strongly supported clade ..." (Tagliaro et al., 1997). These statements indicate the uncertainty concerning the evolutionary relationships among many of the marmoset species belonging to the South American genus Callithrix. In their study, Tagliaro et al. (1997) sampled the mtDNA control region of $2-5$ individuals from nine species of 
marmosets. The phylogenetic confusion is reflected in the placement of different individuals belonging to the same morphological species into more than one clade (Fig. 2); this results in paraphyly for certain marmoset species (Tagliaro et al., 1997). One likely explanation for the placement of members of a single species into different, well-supported clades is that there has been natural hybridization and introgression leading to a reticulate phylogenetic signal. This hypothesis is supported by the observation of parapatric distributions and hybrid zones between several of the species (Tagliaro et al., 1997; Marroig et al., 2004). However, it has also been hypothesized that one of the marmoset species, C. kuhli originated from hybridization between C. geoffroyi and C. penicillata. But, on the basis of 39 skull traits, Marroig et al. (2004) argued against this hypothesis. In contrast, it seems significant that the analysis of mitochondrial DNA variation by Tagliaro

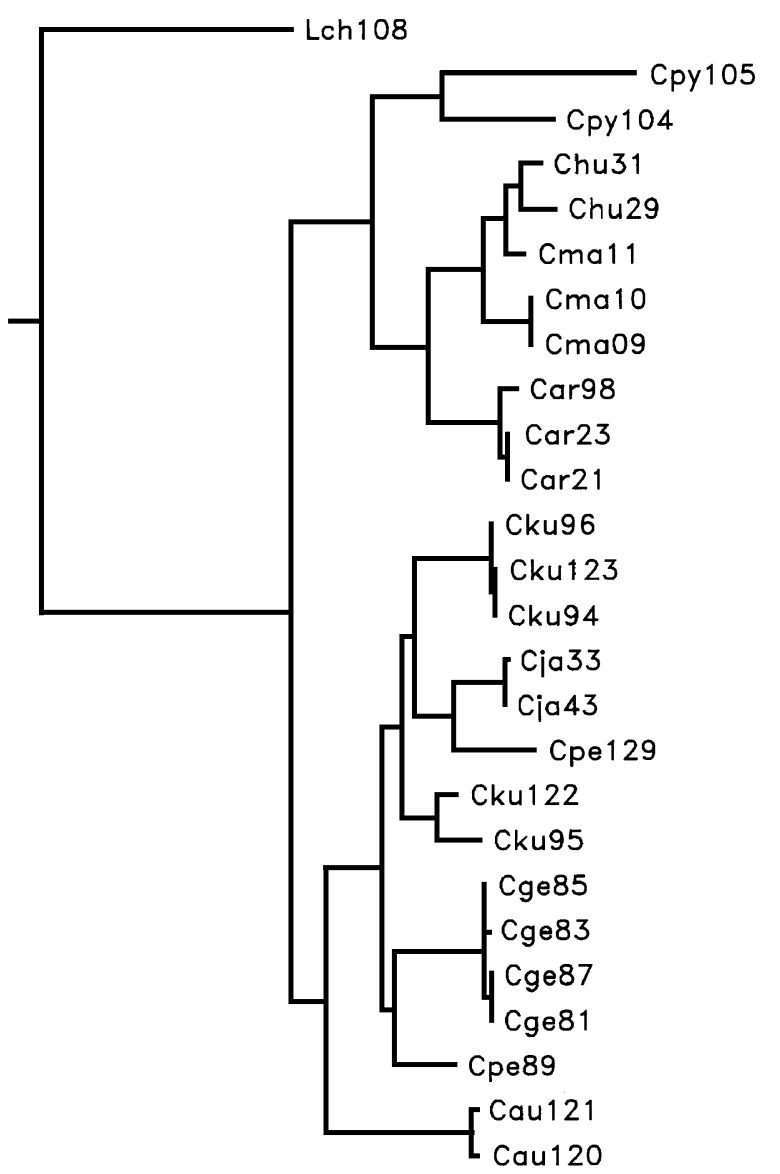

Fig. 2. Maximum-likelihood phylogeny for species of marmoset (genera Callithrix and Cebuella) based upon mtDNA control region sequences. Branch lengths indicate sequence change. $C$. argentata $=$ Car21, 23, 98; C. aurita $=$ Cau120, 121; . geoffroyi $=\mathrm{Cge81}$, 83, 85, 87; . humeralifer $=\mathrm{Chu29,}$ 31; C. jacchus $=$ Cja33, 43; C. kuhli $=$ Cku94-96; C. mauesi $=$ Cma9-11; C. penicillata $=$ Cpe89, 129; Cebuella pygmaea $=$ Cpy104, 105; Leontopithecus chrysomelas (Outgroup) $=$ Lch108 (from Tagliaro et al., 1997). et al. (1997) found that the C. kuhli individuals fell into two clades separated by haplotypes found in $C$. penicillata and C. jacchus (Fig. 2; Tagliaro et al., 1997). This phylogenetic pattern supports an hypothesis of hybrid origin for these five C. kuhli individuals leading to the apparent paraphyly, but with $C$. penicillata and $C$. jacchus as the progenitors instead of C. penicillata and C. geoffroyi.

Tamarins (genus Saguinus) are closely allied with marmosets and, depending upon the taxonomic treatment (see Cropp et al., 1999 for a discussion), have been placed within a common subfamily or family. Additional support for the effect of reticulation on the evolution of New World primates comes from studies of molecular variation among tamarin species as well. Mitochondrial DNA-based phylogenetic reconstructions thus found discordant patterns for several species. Cropp et al. (1999) documented the placement of $S$. fuscicollis fuscus away from other fuscicollis subspecies in a clade with $S$. nigricollis, and $S$. $f$. lagonotus in a clade with $S$. tripartitus. It is important to note that these authors did not infer natural hybridization as the cause of discordance between the morphological and mtDNA data. Instead, they argued (i) that lack of resolution explained the support for the lagonotus/ tripartitus assemblage and (ii) that subspecies fuscus should be elevated to specific status, resolving the problem of its phylogenetic association with $S$. nigricollis (Cropp et al., 1999). Heretofore unrecognized species, incomplete lineage sorting and the retention of ancestral polymorphism, three major causes for incongruent genetic and organismal lineages among groups of young species, remain possible alternatives to the hybridization hypothesis. However, if reticulate evolution within tamarins has occurred-as it has in the closely related marmoset clade - the discordance between the morphological and mtDNA data is expected.

\section{Old world primates}

\section{Prosimians (lemurs)}

"The discovery of hybrid zones between lemur populations should not be surprising given the high species richness and close proximity of many related taxa" (Wyner et al., 2002). This sentiment reflects not only the marvelous taxonomic diversity of prosimians but also likewise the genetic diversity provided by the process of introgressive hybridization. In this case, hybridization has apparently contributed to the genetic structure of the complex taxonomic assemblages of Madagascar lemurs. As an example, Wyner et al.'s (2002) study of a putative hybrid zone (Fig. 3) between three lemur species, Eulemur fulvus rufus, Eulemur albocollaris and Eulemur collaris, detected genotypes indicative of interspecific recombination. Though 


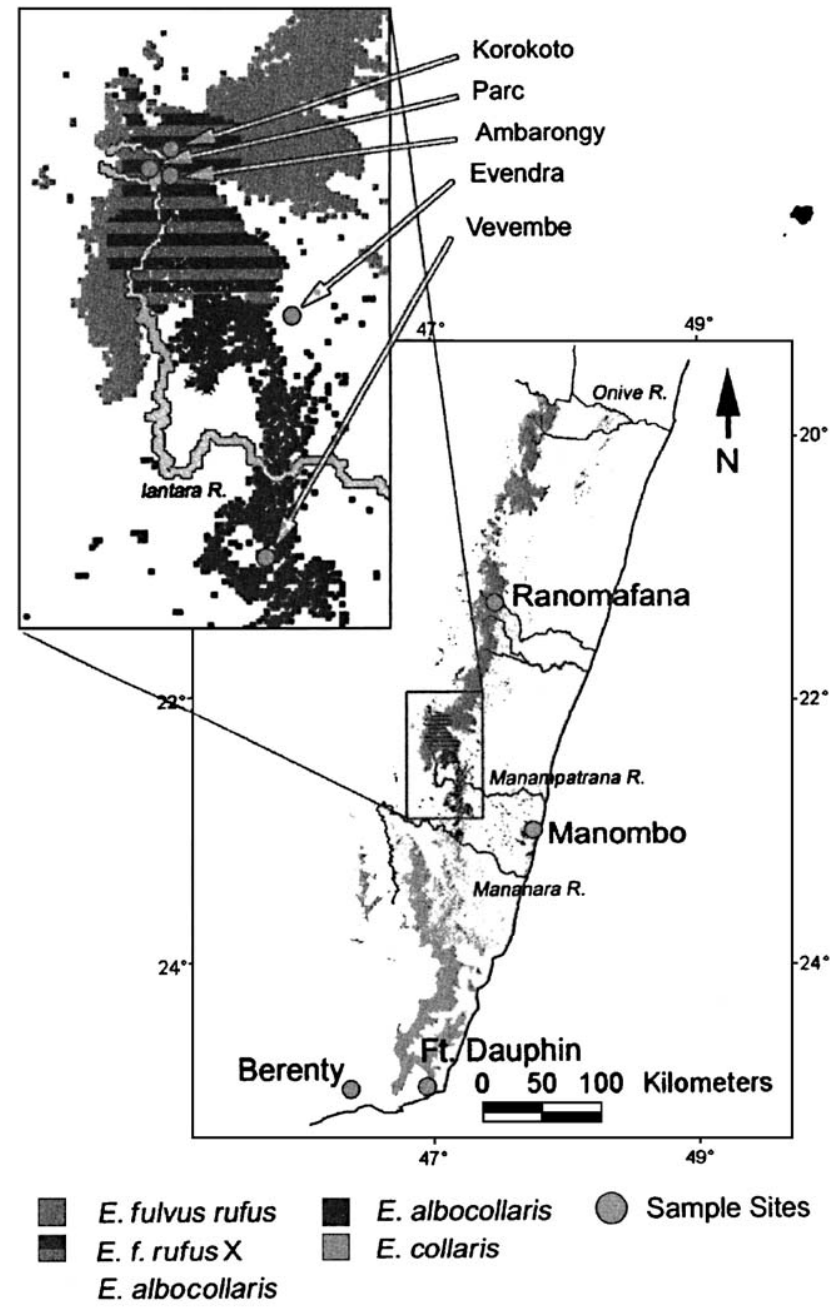

Fig. 3. Distribution of two brown lemur species, Eulemur fulvus/E. albocollaris and their hybrid zone in eastern Madagascar (from Wyner et al., 2002).

involving only the first two of these species, of the 21 individuals sampled from the area of parapatry, only three demonstrated non-hybrid genotypes (Table 1), and these latter individuals possessed hybrid-like morphologies (Wyner et al., 2002). Indeed, it is probable that the non-concordance between the phenotypic (i.e. hybridlike) and genotypic (i.e. E. albocollaris) markers present in these three individuals reflects introgression of genes underlying the morphological characteristics of E. fulvus into $E$. albocollaris without a concomitant introgression of mitochondrial D-loop or nuclear intron marker loci. Such disagreement between data sets is expected for hybrid zones that contain advanced generation filial or backcross hybrids in which recombination has broken up associations between loci (Arnold, 1997; Burke and Arnold, 2001).

The sifaka, genus Propithecus, represents another lemur species complex that likely reflects the interacting processes of divergent and reticulate evolution. We would suggest that the observation of Pastorini et al. (2001) that "There are many cases [in sifakas] in which molecular or morphological data are found to be positively misleading ..." might reflect the interaction of genotypic divergence and admixture. Indeed, the detailed phylogenetic and phylogeographic work of Pastorini et al. (2001, 2003) resolved paraphyletic relationships for some subspecies. Furthermore, uncertainty over whether lemur taxa should be awarded subspecific or specific status (e.g. Mayor et al., 2004) may reflect the limitations of capturing merely a snapshot of the genetic signatures from cycles of divergent evolution and reticulation.

\section{Colobines (langurs)}

As members of the subfamily Colobinae within the family Cercopithecidae, the Asian leaf monkeys or langurs, along with their sister-clade of African colobus monkeys, demonstrate a unique fermentation system for primates. These species possess both a complex foregut, where leaf material is fermented by bacteria, and a true stomach in which large levels of bacteriolytic lysozyme are expressed (Messier and Stewart, 1997). The uniqueness of their digestive physiology notwithstanding, the langurs like other primates demonstrate phylogenetic relationships suggestive of reticulate evolution.

"Within the Javan Trachypithecus auratus, our analysis does not support the distinction of two subspecies $\ldots T$. auratus and $T$. cristatus are not internally monophyletic with respect to each other ..." (Rosenblum et al., 1997). This conclusion came from an analysis of restriction fragment length polymorphism in the mitochondrial NADH from these two Asian leaf monkey species. Sampling 1-15 individuals of $T$. auratus, T. cristatus and the related langur, Presbytis comata, from Javan, Malaysian and Sumatran populations, Rosenblum et al. (1997) discovered phylogenetic admixture of the two Trachypithecus species. This admixture was not reflective of a paucity of haplotypes resulting in low phylogenetic resolution. In fact, haplotype diversity was high both within and between the taxa. Though such diversity is also a function of effective population size (Avise, 1994), the haplotypes detected in this study clustered into groups not reflective of morphological similarity. Rosenblum et al. (1997) used the paraphyly observed for the mitochondrial haplotypes from $T$. auratus and $T$. cristatus to suggest that, for conservation efforts, this species pair should be considered only " $\ldots$ one large polymorphic, conservation unit". However, once again the non-concordant results from the phenotypic and molecular characters can be interpreted instead as resulting from sexual reproduction leading to introgression of only a portion of the genetic markers. Specifically, introgression between the langur species may have resulted in the transfer of the mitochondrial genomes, but not the genes 
Table 1. Distribution of genetic markers in individuals of lemurs designated as hybrids between E. albocollaris and E. f. rufus

\begin{tabular}{|c|c|c|c|c|c|c|c|c|c|c|}
\hline \multirow[t]{2}{*}{ Sample } & \multicolumn{2}{|l|}{ Dloop } & \multicolumn{2}{|l|}{ Hemopexin } & \multicolumn{2}{|c|}{ Malic enzyme } & \multicolumn{2}{|c|}{ Microsatellite 26} & \multirow{2}{*}{$\begin{array}{l}\text { Samples w/ } \\
\text { albocollaris } \\
\text { markers }\end{array}$} & \multirow{2}{*}{$\begin{array}{l}\text { Samples w/ } \\
\text { rufus } \\
\text { markers }\end{array}$} \\
\hline & Albocollaris & Rufus & Albocollaris & Rufus & Albocollaris & Rufus & Albocollaris & Rufus & & \\
\hline Hybrid 173 & $\mathrm{X}$ & - & $\mathrm{X}$ & $*$ & * & $*$ & $\mathrm{X}$ & $\mathrm{X}$ & $\mathrm{X}$ & $\mathrm{X}$ \\
\hline Hybridl77 & - & $\mathrm{X}$ & $*$ & $\mathrm{X}$ & * & $*$ & $\mathrm{X}$ & - & $\mathrm{X}$ & $\mathrm{X}$ \\
\hline Hybrid 182 & - & $\mathrm{X}$ & $*$ & $*$ & * & $*$ & $\mathrm{X}$ & $\mathrm{X}$ & $\mathrm{X}$ & $\mathrm{X}$ \\
\hline Hybrid 185 & - & $\mathrm{X}$ & $\mathrm{X}$ & $\mathrm{X}$ & $*$ & $\mathrm{X}$ & $\mathrm{X}$ & $\mathrm{X}$ & $\mathrm{X}$ & $\mathrm{X}$ \\
\hline Hybrid 186 & - & $\mathrm{X}$ & $*$ & $\mathrm{X}$ & $*$ & $\mathrm{X}$ & $\mathrm{X}$ & - & $\mathrm{X}$ & $\mathrm{X}$ \\
\hline Hybrid 231 & $\mathrm{X}$ & - & $\mathrm{X}$ & $*$ & $*$ & $*$ & $\mathrm{X}$ & $\mathrm{X}$ & $\mathrm{X}$ & $\mathrm{X}$ \\
\hline Hybrid 232 & - & $\mathrm{X}$ & $\mathrm{X}$ & $*$ & * & $*$ & - & $\mathrm{X}$ & $\mathrm{X}$ & $\mathrm{X}$ \\
\hline Hybrid 233 & $\mathrm{X}$ & - & $*$ & $*$ & $*$ & $*$ & - & $X$ & $\mathrm{X}$ & $\mathrm{X}$ \\
\hline Hybrid 234 & $\mathrm{X}$ & - & $X$ & $*$ & * & $*$ & $X$ & - & $X$ & - \\
\hline Hybrid 235 & $\mathrm{X}$ & - & $*$ & $X$ & * & $*$ & - & $X$ & $\mathrm{X}$ & $X$ \\
\hline Hybrid 236 & $\mathrm{X}$ & - & $\mathrm{X}$ & $*$ & $*$ & $*$ & $\mathrm{X}$ & - & $\mathrm{X}$ & - \\
\hline Hybrid 237 & $\mathrm{X}$ & $\mathrm{X}$ & $*$ & $*$ & * & $*$ & $\mathrm{X}$ & $X$ & $\mathrm{X}$ & $X$ \\
\hline Hybrid 238 & $\mathrm{X}$ & - & $*$ & $*$ & $*$ & $*$ & $\mathrm{X}$ & $X$ & $\mathrm{X}$ & $\mathrm{X}$ \\
\hline Hybrid239 & $\mathrm{X}$ & - & $\mathrm{X}$ & $*$ & $*$ & $*$ & - & $\mathrm{X}$ & $X$ & $\mathrm{X}$ \\
\hline Hybrid 265 & $X$ & - & $X$ & $*$ & * & $*$ & $X$ & - & $X$ & $\mathrm{X}$ \\
\hline Hybrid 266 & $\mathrm{X}$ & - & $\mathrm{X}$ & $*$ & $*$ & $X$ & $\mathrm{X}$ & $\mathrm{X}$ & $\mathrm{X}$ & $\mathrm{X}$ \\
\hline Hybrid 267 & $\mathrm{X}$ & - & $X$ & $*$ & $*$ & $*$ & - & $X$ & $X$ & $\mathrm{X}$ \\
\hline Hybrid 268 & $\mathrm{X}$ & - & $X$ & $*$ & $*$ & $*$ & - & $\mathrm{X}$ & $X$ & $\mathrm{X}$ \\
\hline Hybrid 269 & $\mathrm{X}$ & - & $\mathrm{X}$ & $*$ & $*$ & $*$ & - & $\mathrm{X}$ & $\mathrm{X}$ & $\mathrm{X}$ \\
\hline Hybrid 270 & - & $X$ & $\mathrm{X}$ & $*$ & $*$ & $*$ & - & $\mathrm{X}$ & $\mathrm{X}$ & $\mathrm{X}$ \\
\hline Hybrid 271 & - & $X$ & $X$ & $*$ & $*$ & $*$ & $X$ & $X$ & $X$ & $\mathrm{X}$ \\
\hline Total & 13 & 8 & 14 & 4 & 0 & 3 & 13 & 16 & 21 & 18 \\
\hline
\end{tabular}

Numbers after species name correspond to the American Museum of Natural History Identification. "X" indicates that a marker is present, "_-" indicates that the marker is absent and "*”" indicates an ambiguous marker (from Wyner et al., 2002).

underlying morphological traits. Indeed, though not arguing in favor of reticulation, Rosenblum et al. (1997) suggested a behavioral pattern that would lead to introgression of the maternally inherited mtDNA: "However, we suggest that high levels of mtDNA population subdivision are often the product of female philopatry, a social organization exhibited by many mammals and, indeed, most primate species ... Contrariwise, leaf monkeys have a social organization in which females sometimes transfer between groups ..."

\section{Cercopithecine (mangabeys, baboons, macaques)}

The following quotes are instructive for the current discussion: "Widespread papionin taxa (such as Papio baboons and species-groups of the genus Macaca) ... are distributed as a "patchwork" of non-overlapping but often parapatric forms ... 'Hybrid zones' with a wide variety of internal genetic structures and dynamics, typically separate parapatric allotaxa" (Jolly, 2001). "Numerous field reports of hybrid monkeys and documented cases of persistent hybrid zones suggest that natural hybridization is common among African cercopithecines" (Detwiler et al., 2005). Thus, the outcome of hybridization in the form of hybrid zone formation, introgression and the founding of hybrid taxa is apparent in baboons and macaques. In addition, the entire tribe Papionini, which also includes the geladas (Theropithecus), drills and mandrills (Mandrillus), and mangabeys (Cercocebus, Lophocebus) demonstrates genetic and phylogenetic patterns indicative of reticulate evolution (e.g. Shotake et al., 1977; Shotake, 1981; Jolly et al., 1997; Harris and Disotell, 1998; Szmulewicz et al., 1999; Alberts and Altmann, 2001; Dirks et al., 2002; Newman et al., 2004). This conclusion (i.e. that reticulate events have fundamentally affected papionin evolution) can be illustrated by sampling at two temporal scales: (i) with phylogenetic assessments for the tribe as a whole and (ii) with analyses of contemporary hybrid zones.

In an analysis of five, unlinked, nuclear loci, Harris and Disotell (1998) defined evolutionary relationships among the various papionin genera, with particular emphasis placed on defining the phylogenetic placement of species from the two mangabey genera, Cercocebus and Lophocebus. The results indicated that species from these two genera belonged to separate clades containing other members of the papionin tribe. In addition, a phylogeny based on mitochondrial COII gene sequences also revealed widespread paraphyly for the mangabey genera (Disotell, 1994). Finally, the mitochondrial and some (but not all) of the nuclear gene trees revealed discordance (Harris and Disotell, 1998) in the placement 
of Papio (baboon) and Theropithecus (gelada) as well. These taxa resolved as sister lineages in some trees, but not in others. Harris and Disotell (1998) suggested that incomplete lineage sorting or reticulation could account for the patterns of phylogenetic discordance among the papionin genera. However, they concluded that (i) "It is significant that hybridization has been reported in wild and captive populations of Papio and Theropithecus ..." and (ii) "Hybridization between papionin species with subsequent introgression ... may lead genera to falsely appear as sister taxa ..." It is therefore likely that, as papionin evolution proceeded, this tribe was repeatedly impacted by bouts of introgressive hybridization. This introgression included the progenitors of what are now recognized as different genera.

Reticulate evolution within the papionin tribe is also affecting the genetic structure of contemporary populations. This is seen clearly in two well-defined instances of hybridization involving three species of baboons. The first occurs in the Awash National Park, Ethiopia. This zone of overlap and hybridization involves the olive (Papio anubis) and hamadryas (Papio hamadryas) baboons. Species-specific morphology, blood proteins, Alu repeat elements and mitochondrial DNA markers indicate that hybridization between these species has resulted in bi-directional, but asymmetric, introgression with gene flow proceeding largely from hamadryas into anubis (Shotake et al., 1977; Szmulewicz et al., 1999; Jolly, 2001; Newman et al., 2004). The second zone located in Amboseli, Kenya also involves $P$. anubis, but with a third species, $P$. cynocephalus (i.e. yellow baboon). Though both hybrid zones are characterized by numerous recombinant genotypes, the olive/hamadryas phenotypic structure demonstrates a bi-modality (i.e. hybrids are morphologically olive-like or hamadryas-like) whereas the olive/yellow hybrid zone showed a continuous phenotypic distribution from the yellow to olive morphologies (Alberts and Altmann, 2001). Consistent with the continuous phenotypic distribution is the finding that mitochondrial haplotype distributions do not separate phylogenetically, likely because of extensive introgression between anubis and cynocephalus (Newman et al., 2004). Furthermore, the frequency of hybridization and introgression is increasing in this zone (Fig. 4), most likely due to increased immigration of anubis and hybrid individuals fleeing from habitat destruction (Alberts and Altmann, 2001).

As with the evidence for the baboons and mangabeys, numerous studies comparing molecular and morphological data for species of Macaca have resulted in discordant conclusions/scenarios drawn from different data sets. "For these reasons, paraphyletic mitochondrial DNA haplotypes of many taxa in this study ( $M$. nemestrina, $M$. hecki, $M$. tonkeana, M. ochreata, $M$. nigra) do not necessarily conflict with other research that suggests these groups are morphologically distinct

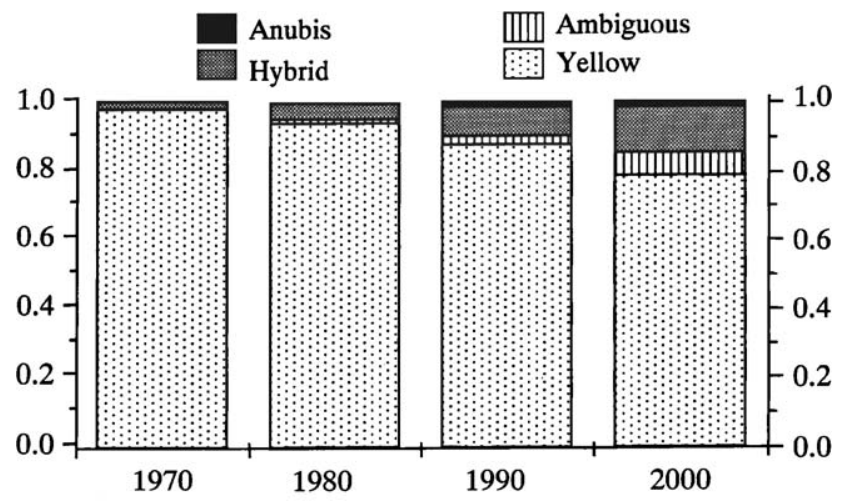

Fig. 4. Relative proportions of baboon species, Papio anubis (i.e. anubis) and P. cynocephalus (i.e. yellow), and their natural hybrids over 30 years of sampling. Animals scored as having "ambiguous" phenotypes may have been hybrids or may have represented an outlying yellow baboon phenotype (from Alberts and Altmann, 2001).

species." With this conclusion, Evans et al. (1999) discusses both numerous instances of introgression within Macaca, and the fundamentally important implications to be considered with regard to conservation efforts. Specifically, this study and others (Hayasaka et al., 1996; Bynum et al., 1997; Morales and Melnick, 1998; Tosi et al., 2000, 2002, 2003; Evans et al., 2001, 2003; Bynum, 2002; Kawamoto, 2005; Smith and McDonough, 2005) detected natural hybridization and introgression involving ca. 15 species.

Though each of the above studies within Macaca is a detailed analysis of hybridization and introgression among this diverse array of taxa, we can illustrate the general conclusions using the single example of Tosi et al. (2003). This analysis reported molecular variation for loci inherited maternally, paternally or bi-parentally. Tosi et al. (2003) contrasted the power of this approach to studies relying on a single type of genetic marker. These authors concluded that, “... episodes of reticulate evolution often go undetected in analyses employing a single genetic system". In contrast, their studies detected non-concordant phylogenies and paraphyly for several species, including $M$. fascicularis and $M$. mulatta. Furthermore, they inferred a hybrid speciation event in which members of the $M$. sinica and $M$. fascicularis species complexes (i.e. "proto-M. assamensis/thibetana"; Tosi et al., 2003) hybridized to form the $M$. arctoides lineage. This hybrid speciation event most likely took place when the Macaca species existed in the setting of a Pleistocene forest refugium. Past hybridization resulting in contemporary hybrid species would yield the admixture of markers present in two ancestral, divergent lineages. The hybrid speciation hypothesis accounts for not only the discordance between the various marker data for $M$. arctoides, but also its unique sexual anatomy including a unique glans penis and 
baculum structure in males and a reciprocal vaginal and exocervix morphology in females (Tosi et al., 2000). Reticulate evolution in Macaca is seen to be creative in both genotypic diversity and in the formation of new, hybrid taxa.

\section{Hominoids/gibbons}

"There are several competing hypotheses on the phylogenetic relationships of species within subgenus Hylobates ... these gibbon species are closely related, hybridization is possible, and this may be the source of incongruent phylogenetic relationships ..." (Noda et al., 2001). Indeed, the expectation of a close evolutionary and genetic relationship between species of Hylobates (i.e. gibbons) is suggested by the fact that artificial hybridization even between gibbons and siamangs (genus Symphalangus) can produce viable offspring (Myers and Shafer, 1979). It therefore should come as no surprise that hybridization, leading to introgression of nuclear and/or cytoplasmic markers, can take place between species of Hylobates as well.

As expected from the semi-permeable nature of genomes, introgression among the gibbon species results in discordance among phylogenies based upon different data sets. Even individuals belonging to different subgenera may be grouped on the basis of genotype. For example, an analysis of sequence variation in the mitochondrial 16S rRNA gene resulted in the paraphyletic placement of one individual of $H$. pileatus, of the subgenus Hylobates, with $H$. concolor, subgenus Nomascus (Noda et al., 2001). In addition, within the "monophyletic" subgenus Hylobates clade, individuals of $H$. klossii were more closely related to individuals of $H$. agilis or $H$. lar than to other gibbons that morphologically resemble $H$. klossii (Noda et al., 2001). In contrast, Hayashi et al. (1995) had previously found a monophyletic relationship of individuals of $H$. lar and H. klossii. This led Noda et al. (2001) to the conclusion that hybridization "... may be the source of incongruent phylogenetic relationships, depending on the individuals used from the same species".

There is also discordance between gibbon phylogenies at higher systematic levels as well. In particular, which Hylobates taxa are defined as basal varies between studies (Noda et al., 2001; Roos and Geissmann, 2001), though if the basal lineage divergences were temporally closely associated the genetic signal could be small. In any case, it seems likely that evolution within the gibbons has been profoundly affected by natural hybridization.

\section{Hominoids/orangutans}

"Sumatran [orangutan] haplotypes fall into three distinct ... groups. Strikingly, one ... shares sequence identity with the most widespread Bornean haplotype ...". "Alternating periods of geographic isolation and reunion ... presented substantial opportunity for population dispersal between periodically isolated demes" (Muir et al., 2000).

Like gibbons, species of orangutan belong to the superfamily Hominoidea. However, orangutans are then grouped within the family Hominoidea that also includes the human/chimp/gorilla clade (Noda et al., 2001). Several analyses (e.g. Xu and Arnason, 1996; Zhi et al., 1996; Muir et al., 2000; Noda et al., 2001; Warren et al., 2001) included a test for genetic partitioning within and between the orangutan taxa referred to as Sumatran and Bornean, a designation reflecting their island of origin. The orangutans inhabiting these islands differ by two pericentric inversions (on chromosome 2 and the Y-chromosome) and by the presence of a nucleolar organizing region on the distal portion of the long arm of the Y-chromosome (i.e. found in Sumatran but not Bornean individuals; Xu and Arnason, 1996). Furthermore, several studies of the orangutans from these two regions found equivalent or greater levels of DNA sequence divergence relative to other species (e.g. pygmy and common chimpanzees) or even genera (e.g. Homo and Pan) of primates (Xu and Arnason, 1996; Zhi et al., 1996). Although most workers refer to the orangutan taxa in question as subspecies (i.e. Bornean, Pongo pygmaeus pygmaeus; Sumatran, $P$. $p$. abelii) the extensive divergence has led some investigators to designate them as separate species (e.g. P. pygmaeus and P. abelii; $\mathrm{Xu}$ and Arnason, 1996). Indeed, the genetic distances calculated from mitochondrial (RFLP and 16S sequences) and nuclear (minisatellite) loci resulted in a calculated divergence time from a common ancestor of 1.5-1.7 mya and to the conclusion that this divergence occurred "... well before the two islands separated and long enough [ago] for species-level differentiation" (Zhi et al., 1996).

Notwithstanding their genetic distinctiveness, the Bornean and Sumatran taxa are capable of forming fertile offspring in captivity (Xu and Arnason, 1996). Furthermore, the evidence that orangutans have been impacted by reticulate evolution comes from discordant results from different molecular studies. On the one hand, several studies that utilized mtDNA sequence variation found reciprocal monophyly for the Sumatran and Bornean taxa (Xu and Arnason, 1996; Noda et al., 2001; Warren et al., 2001). However, one study of mitochondrial DNA variation sampled from multiple individuals detected “ '... 'Borneo' haplotypes from several individuals that could be traced to Sumatra ..." (Muir et al., 2000). As concluded for gibbons, and other primates, hybridization between divergent lineages of orangutans may also account for “... incongruent phylogenetic relationships, depending on the individuals used from the same species" (Noda et al., 2001). 


\section{Hominoids/chimpanzees and bonobos}

Phylogenetic analyses show the sequences from the different chimpanzee subspecies to be intermixed ... some chimpanzees are more distant from each other than they ... are from bonobos (Kaessmann et al., 1999).

Kaessmann et al. (1999) examined an approximately $10,000 \mathrm{bp}$ region of the $\mathrm{X}$ chromosome from individuals belonging to three chimpanzee subspecies (central African, Pan troglodytes troglodytes; western African, $P$. $t$. verus; eastern African $P$. $t$. schweinfurthii) and bonobos (Pan paniscus). Their results (Fig. 5) led them to the following conclusion: "The absence of subspeciesspecific clusters is notable in view of mtDNA studies indicating that chimpanzee subspecies are very old." As discussed by these authors, the large amount of mtDNA divergence and the times since divergence of the subspecies based upon these values (ca. 1.5-2.5 mya; Pesole et al., 1992; Morin et al., 1994) has been the basis for suggesting that the western African form be elevated

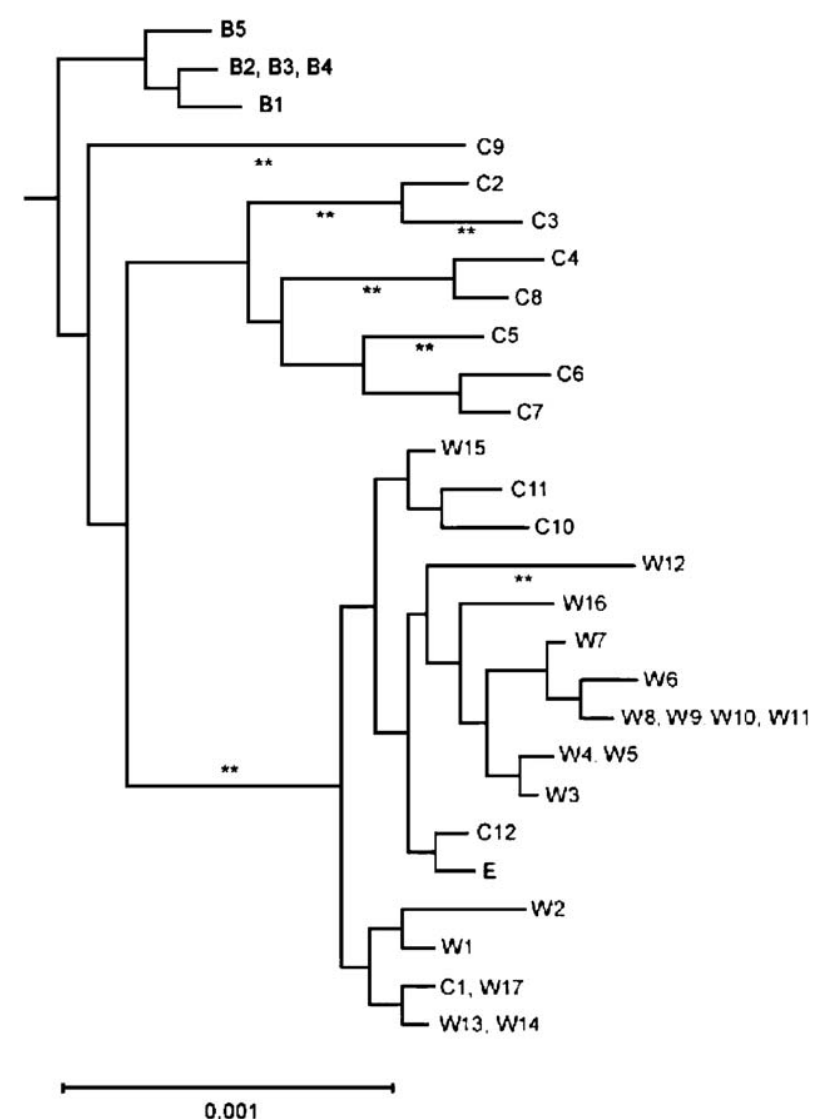

Fig. 5. Maximum likelihood phylogeny for chimpanzee and bonobo individuals derived from an approximately 10,000 bp, $\mathrm{X}$ chromosome-specific sequence. "B" = bonobo; "C", "E" and "W" = central, eastern and western chimpanzee subspecies. Double asterisks (i.e. **) indicate branches of significantly positive length (from Kaessmann et al., 1999). to specific status (Morin et al., 1994). Yet, comparing the mitochondrial data with the $\mathrm{X}$ chromosome sequence data leads to the conclusion that natural hybridization and introgression of $\mathrm{X}$ chromosome sequences has occurred between the subspecies, while at the same time the mitochondrial DNA has not been exchanged. Interestingly, Stone et al. (2002) concluded that $\mathrm{Y}$ chromosome specific sequences, like mtDNA, had not introgressed between subspecies of chimpanzee. However, included in their samples was an individual that possessed a $\mathrm{Y}$ chromosome haplotype characteristic of $P$. t. verus, but a mitochondrial haplotype characteristic of the recently named subspecies, $P . t$. vellerosus (Stone et al., 2002).

In addition to gene flow among the various chimpanzee subspecies, the $\mathrm{X}$ chromosome sequence data also detected introgression between the lineages that gave rise to chimpanzees and bonobos. In this case, Kaessmann et al. (1999) inferred a divergence time for the $\mathrm{X}$ chromosome sequences found in $P$. troglodytes and $P$. paniscus of $0.69-1.2$ mya. This estimate is less than half that for other nuclear and mtDNA markers (Kaessmann et al., 1999). To explain this extreme discordance, Kaessmann et al. (1999) inferred that, "... certain loci ... may have crossed the 'species barrier' much later than other loci. Consequently, not only chimpanzee subspecies, but also bonobos and chimpanzees, may have an intermixed genetic relationship". Similarly, Deinard and Kidd (1999) discovered that some HOXB6 intergenic region haplotypes from $P$. paniscus were more similar to $P$. troglodytes haplotypes than to haplotypes from individuals of their own species. In contrast to Kaessmann et al. (1999), Deinard and Kidd (1999) concluded that this resulted from incomplete lineage sorting from a polymorphic, ancestral population. Likewise, Won and Hey (2005) found no evidence for gene flow between chimpanzees and bonobos. However, they did conclude that unidirectional introgression had occurred between different chimpanzee subspecies (Won and Hey, 2005).

It is expected that coalescence will occur more quickly for the mitochondrial genome, given its smaller $\mathrm{N}_{\mathrm{e}}$ relative to the nuclear genome (e.g. see Avise et al., 1984; Avise, 1994). Thus, as concluded by Deinard and Kidd (1999) one explanation for the discordance between the nuclear and mitochondrial markers is retention of ancestral polymorphisms for the more slowly coalescing nuclear alleles. However, the repeated finding of admixtures between both chimpanzee subspecies and between chimpanzees and bonobos-leading to some chimpanzees being more similar to bonobos in their nuclear sequences than to chimpanzees belonging to their own subspecies - strongly supports the reticulate hypothesis. While incomplete lineage sorting is a plausible alternative, the findings for the HOXB6 locus are clearly, as is apparently the case for the $\mathrm{X}$ and $\mathrm{Y}$ 
chromosome-specific loci, also consistent with a reticulate evolutionary history for chimpanzees and bonobos.

\section{Hominoids/gorillas, chimpanzees, humans}

The famous "trichotomy" problem, the phylogenetic relationships among chimps, gorillas and humans, has been debated for decades and during the last 10 years or so a consensus has been reached that groups humans and chimps to the exclusion of gorilla. Yet, as reflected by O'hUigin et al. (2002), "Perhaps the best-known example of prolonged controversy ... [regarding phylogenetic placement] ... is the one involving the human species ... The consensus approach identifies the chimpanzee as the nearest living relative of humans, but the evidence supporting this conclusion is not overwhelming ... Inconsistency in the inferred patterns of shared-derived substitutions ... is apparent both between and within loci of the three species comprising the trichotomy."

One explanation for the above "inconsistencies" is of course reticulation. The signature of reticulation in primates can thus also be inferred for the clade that includes humans and our sister-species, chimpanzees and gorillas. Data suggesting reticulate evolution among the progenitors of Gorilla, Pan and Homo comes from a variety of genetical data sets. For example, using chromosome structure as a means of discerning evolutionary events, Richard et al. (2000) proposed a dichotomously branching tree for hominoids including the gorilla, chimpanzee and human clade. However, their ultimate conclusion was that a dichotomous tree was an oversimplification and when more chromosomal data were available "... a network ..." (i.e. a reticulating phylogeny) would most likely be resolved (Richard et al., 2000).

Analyses of DNA sequence variation within the human, chimpanzee, and gorilla clade also suggest the role of introgression in affecting the genetic composition and evolution of these species. Yet, such patterns have often led to the inference that ancestral polymorphism and incomplete lineage sorting, rather than reticulation explain the findings (see Arnold, 1997 for a discussion). Two examples involving the human/chimp/gorilla clade come from (i) a study of Alu sequences (Salem et al., 2003) and (ii) an analysis of 57 DNA segments derived from 51 loci (O'hUigin et al., 2002). In both cases, the presence of variation not fitting the model of a dichotomously branching tree was assigned mainly to incomplete lineage sorting of ancestral polymorphisms. This included Alu variants found in Homo and Gorilla (Salem et al., 2003). Interestingly, these authors discuss a similar example (Takahashi et al., 2001) of an a SINE element shared among cichlid species, presumably due to incomplete lineage sorting. However, in the case of the cichlid species Salem et al. (2003) issued the warning that "... interspecific hybridization could also be invoked ...". The question of why introgression could not likewise explain the phylogenetic incongruence in the gorilla/chimpanzee/human clade is not discussed. Significantly, the complete sequence of chromosome 22 in chimpanzees and its orthologue, chromosome 21 , in humans was recently published (Watanabe et al., 2004). A phylogenetic tree of $A l u$ sequences inserted into these chromosomes, subsequent to the speciation of Homo and Pan, also detected interspecific admixtures (Watanabe et al., 2004). This reflected greater sequence similarity between sequences from the different genera than between sequences from the same species. Similarly, the study of genic diversity at 51 loci (O'hUigin et al., 2002) also detected a large frequency of non-concordant genetic variation among these three taxa.

The findings from the above analyses are consistent with introgressive hybridization giving rise to a reticulate, rather than a simply dichotomous, relationship among humans, chimpanzees and gorillas. Indeed, Navarro and Barton (2003) concluded exactly this in a comparison of sequence evolution in rearranged and colinear portions of the human and chimpanzee genomes. These authors constructed a model to test whether positively selected mutations that differentiate $P a n$ and Homo accrued more often in rearranged portions of the genome, presumably where new adaptations would be protected from recombination. The purpose of this study was to test for changes that might reflect the speciation process. However, Navarro and Barton (2003) also concluded that, as argued in this review, divergent evolution occurred in the context of reticulation. This is summed up well in a review of Navarro and Barton's findings: "The present paper ... suggests that the most famous speciation event of all represents a kind of speciation with gene flow ..." (Rieseberg and Livingstone, 2003). Similarly, an analysis of coding and non-coding genomic regions led Osada and $\mathrm{Wu}$ (2005) to conclude that there was "... a prolonged period of genetic exchange during the formation of these two species" (i.e. chimpanzees and humans). Interestingly, Prager and Wilson (1975) presaged this conclusion nearly 30 years before Navarro and Barton's analysis. Prager and Wilson reported that mammalian taxa ceased to produce hybrids 2-3 million years after divergence from a common ancestor (see Fitzpatrick (2004) for a recent discussion of, and support for, Prager and Wilson's hypothesis). Applied to the human/chimp/gorilla clade, it is apparent that these species were capable of introgressive hybridization for at least half of the 4-6 million years since diverging from a common ancestor. It is not surprising then that, like other primates, humans and their sister taxa exchanged portions of their genomes while diverging. 


\section{Hominoids/australopithecines}

Several possible examples of interspecific reticulation in human evolution exist. A relatively non-controversial one involves East African Australopithecus ("Paranthropus") boisei and South African $A$. robustus. Interbreeding between these taxa could have occurred much in the way that it does in the contact zone between parapatric populations of East African yellow baboons and South African chacma baboons ... (Holliday, 2003).

The evidence for this portion of our review must come from studies of fossil lineages. Testing for reticulate evolution with these data-like testing any evolutionary hypothesis with fossil arrays - presents special difficulties. As we will discuss below, introgression between recently derived hominoid species (i.e. Homo sapiens and $H$. neanderthalensis) can be examined, albeit also with some serious limitations, using molecular markers (e.g. Krings et al., 1997). However, testing for hybridization and introgression between extinct lineages depends usually upon the analysis of fossil, morphological variation, thereby looking for patterns consistent with interbreeding. We feel that it is instructive to consider two, non-primate examples to illustrate such analyses.

The first example involves species of the snail genus Cerion. An examination of fossil and extant species found on the island of Great Inagua (Goodfriend and Gould, 1996) traced the development of hybrid zones and introgressed populations across many millennia. In one instance, the existing population was derived from hybridization between a fossil species that went extinct some 13,000 years ago and an extant species still found in areas near the hybrid zone. In a second case, a hybrid zone persisted for thousands of years even though one of the parents had become extinct (Goodfriend and Gould, 1996). This latter observation, i.e. persistence of a hybrid zone in the absence of continued hybridization and introgression, led to the conclusion that "... the mixed population evolved selected developmental and genetic uniqueness of its own, thus permitting the production of stable novelty by hybridization" (Goodfriend and Gould, 1996).

The second example comes from analyses of fossil sequences of the cladoceran genus Bosmina. Hofmann (1991) utilized these sequences to test for patterns of morphological variation consistent with that expected given introgressive hybridization. In particular, Hofmann (1991) examined the variation in the mucro length ("... distance between the end of the mucros and the nearest point on an auxiliary line indicating a rounded, spineless ventral-caudal angle of the carapace"; Hofmann, 1991) of Bosmina in a sediment core from the Untersee (a small shallow basin) of Lake Constance. Hofmann (1991) concluded that the pattern of morphological variation through time in the Lake Constance,
Untersee cladocera species might be due to introgression. He proposed the following four-part process: (i) the sole occurrence of $B$. longispina; (ii) the invasion of Lake Constance by the second, smaller species $B$. coregoni f. kessleri; (iii) hybridization between these two species, leading to a continuous distribution of sizes including that characteristic of each species as well as intermediate forms; and (iv) the replacement of the two species with hybrid genotypes that were intermediate in size relative to their progenitors (Hofmann, 1991). Thus, the fossil data for Cerion and Bosmina reflect evidence for both introgressive hybridization and the formation of stabilized hybrid lineages (i.e. subspecies or species).

As indicated at the beginning of this section, the close sister-relationship and the synchrony of fossils of Australopithecus boisei and $A$. robustus led to the conclusion that "... where there was [geographic] overlap one might expect some degree of hybridization ..." (Holliday, 2003). Another hypothesis to explain a portion of the morphological variation found among australopithecine species involves a hybrid speciation event resulting in $A$. robustus. In this instance, $A$. africanus apomorphic features also present in $A$. robustus are explained by hybridization between the former species and A. boisei (Holliday, 2003). The resulting lineage would thus be a stable hybrid derivative of the type found in extant animal and plant species complexes (e.g. DeMarais et al., 1992; Rieseberg et al., 1990; Arnold, 1993).

\section{Hominoids/Homo}

"Two conflicting evolutionary models of modern human origins have emerged ... complete replacement, in which modern humans are a new species that replaced all archaic populations, and multiregional evolution, in which modern humans are the present manifestation of an older worldwide species with populations connected by gene flow ..." (Wolpoff et al., 2001). Given the evidence from other primates, it would be logical to conclude that the observation of synchronic and spatial overlap between archaic and modern humans would have resulted in some level of gene flow. Instead, this topic has generated enormous debate. This is indeed surprising based on the evidence that quite distinct, contemporary primate species are involved in introgressive hybridization. However, conclusions from numerous studies of our own species have been anything but unanimous.

It is possible that a portion of the debate over the evolutionary relationship between sapiens and archaic taxa results from a concern that some well-defined Homo species might cease to be recognized taxonomically. For example, many resist the idea that hybridization has occurred between $H$. neanderthalensis and $H$. sapiens because, in the words of Tattersall and Schwartz (1999), “... longterm hybridization ... would indicate 
that the two populations belonged to the same species". However, this should not be the case. It is not appropriate that the application of a given species concept (i.e. "biological species concept": species are populations of individuals reproductively isolated from other such groups of populations; Dobzhansky, 1937; Mayr, 1942) should result in the placement of hybridizing taxa into the same species (Hey et al., 2003). Indeed, Arnold (1997) found that evidence of past or contemporary hybridization has historically been used as only one source of data for determining the systematic placement of taxa. For the current discussion, it is most important that we reiterate the observation that reticulation is a part of the evolutionary process - as much for primates as for plants, or insects, etc. As primates diverge they will continue to introgress with related taxa even though, on the basis of morphology, behavior, ecology, or other traits, they have reached the status of well-defined species (e.g. see Jolly, 2001 for a discussion).

There are many studies designed to test the "replacement" (i.e. no hybridization) and "multiregional" (i.e. hybridization) hypotheses (e.g. Krings et al., 1997; Duarte et al., 1999; Ovchinnikov et al., 2000; Schillaci and Froehlich, 2001; Hawks and Wolpoff, 2001; Wolpoff et al., 2001; Templeton, 2002, 2005; Caramelli et al., 2003; Garrigan et al., 2005). Of the studies that support replacement of $H$. neanderthalensis by $H$. sapiens, the most telling are those that define mitochondrial DNA variation present both in modern humans and Neanderthals (e.g. Krings et al., 1997; Ovchinnikov et al., 2000; Caramelli et al., 2003). In each of these analyses, modern humans always form a separate clade relative to $H$. neanderthalensis samples. Furthermore, in one study that also incorporated 24,000-year-old, Cro-Magnon samples, the ancient mtDNA sequences from CroMagnon individuals showed significantly less divergence from $H$. sapiens than did samples of Neanderthals even though the latter were closer in age to some of the CroMagnon samples (Fig. 6; Caramelli et al., 2003). Pääbo (2003) reflected well the conclusions from these analyses when he stated: "Thus, it seems likely that modern humans replaced archaic humans without extensive interbreeding ..."

In light of the above, it is important to recall the semipermeable nature of genomes (Key, 1968) and the variation in patterns of introgression for cytoplasmic and nuclear elements (e.g. Marchant et al., 1988; Salzburger et al., 2002). For example, we have reviewed the contrasting patterns of introgression between subspecies of chimpanzees and between chimpanzees and bonobos. Thus, mtDNA introgression was not apparent between these taxa, but nuclear introgression apparently did occur following their divergence from a common ancestor (Kaessmann et al., 1999). It would seem that evolutionary patterns in Pan, being our closest living

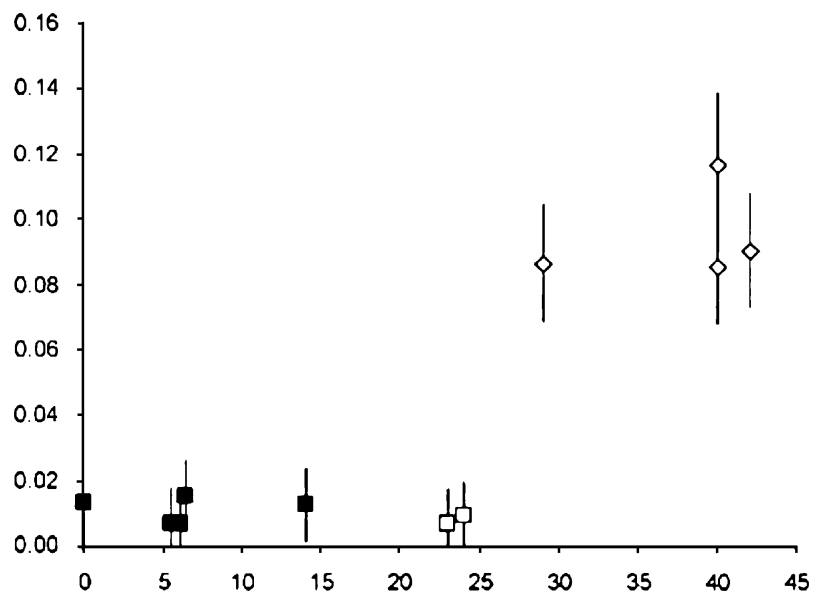

Fig. 6. Average genetic distance between ancient and modern sequences ( $Y$ axes) calculated by comparing mitochondrial hypervariable region I sequences from various aged human samples ( $X$ axes in thousands of years bp) with those found in 2566 modern Europeans. Filled squares = anatomically modern human sequences; open squares = Cro-Magnon sequences; diamonds $=$ Neanderthal sequences (from Caramelli et al., 2003).

primate relative, are a robust model for predicting evolutionary processes in the Homo lineage. If so, the strongest test for introgression between $H$. sapiens and archaic Homo taxa would have to come from nuclear rather than mitochondrial loci. However, it is also important to note that Templeton $(2002,2005)$ concluded that the total evidence from mitochondrial and nuclear DNA variation within Homo lineages actually supported the multiregional rather than the replacement hypothesis. Templeton's findings $(2002,2005)$ indicated that rather than a simple replacement of non-African populations by expansion of populations from Africa, there had been extensive gene exchange throughout the history of the Homo lineages (Fig. 7). This model also explained the results of an earlier study by Takahata et al. (2001) in which they discovered that $10 \%$ of the lineages showed coalescence patterns contradicting an out-of-Africa origin. Likewise, Garrigan et al. (2005) suggested that the pattern of genetic variation detected for the X-linked locus RRM2P4 resulted from "... introgressive hybridization between expanding anatomically modern humans emerging from Africa and archaic populations in Eurasia". These results are thus consistent with a model of extensive introgression between modern and archaic lineages, even after the mitochondrial ancestral lineage had left the African continent.

In addition to the analyses of DNA sequences, the multiregional hypothesis has also been supported by fossil evidence. In particular, the discoveries of individual fossils with apparent admixtures of $H$. neanderthalensis and H. sapiens characteristics (Duarte et al., 1999) 


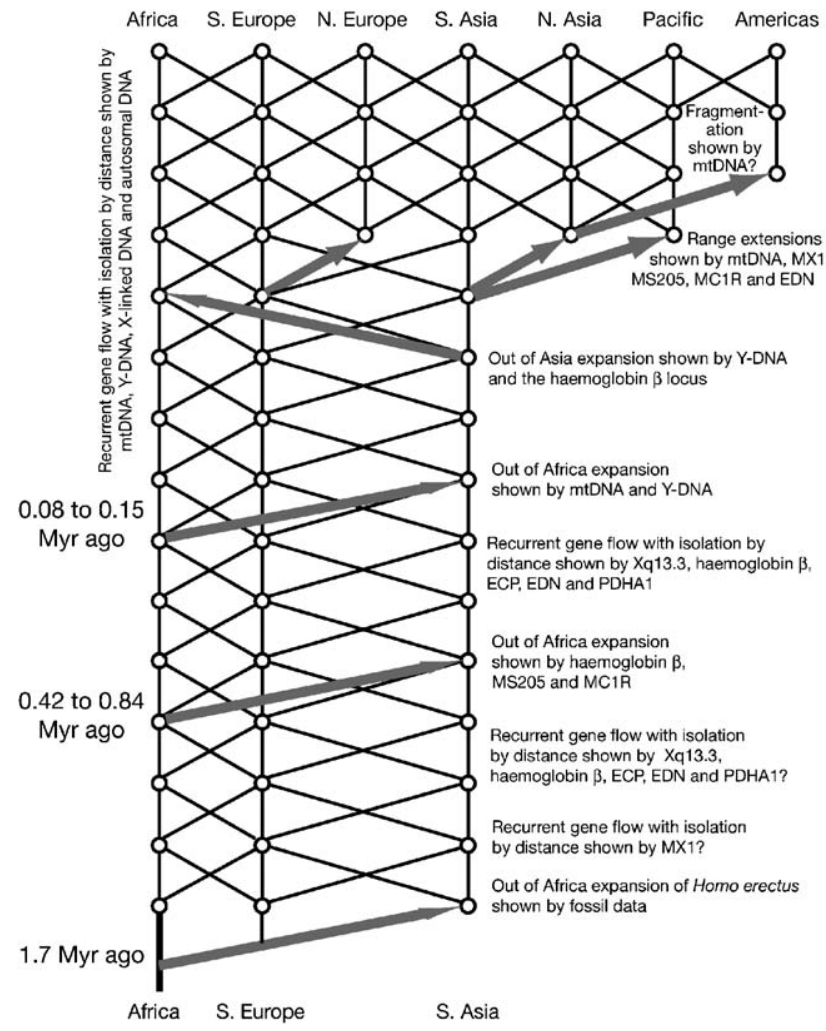

Fig. 7. Model of recent human evolution. Red Arrows indicate major expansion episodes. Vertical lines reflect genetic descent and diagonal lines gene flow events. Question marks indicate inferences lacking resolution at the $5 \%$ level or validated by no more than one genetic locus (from Templeton, 2002).

and populations polymorphic for "archaic" and "modern" morphologies (Wolpoff et al., 2001; Hawks and Wolpoff, 2001) provide additional evidence that Neanderthals did not "go quietly into the night" with regard to gene exchange with $H$. sapiens. Given the evidence for (i) past and contemporary hybridization in numerous primate species complexes, especially within and among the lineages leading to Pan, Gorilla and Homo, (ii) introgression of nuclear and mitochondrial markers between archaic and modern human lineages, and (iii) admixtures of archaic and modern morphological characters in extinct populations, the possibility remains that the genome of Homo also bears the imprint of reticulate evolution.

\section{Conclusions and future directions}

When we reflect upon the evidence presented in this review, we conclude that primates in general have been greatly affected by the process of reticulate evolution. As we have stated in a number of the sections, this should come as no surprise. The pervasive web of genetic connections resulting from natural hybridization is becoming better appreciated as more and more comprehensive, molecular data sets are constructed for a diverse array of animals, plants and microorganisms (Arnold, 2004a, 2006; Arnold and Larson, 2004). Yet, even more important than the documentation of the process of reticulate evolution is the recognition that the tree-of-life metaphor of evolution is not as accurate as a metaphor that can be called the web of life (Arnold, 2006). In this regard, the primates demonstrate the weblike nature that is more reflective of the evolutionary process. Thus, as lineages, of primates as well as all other taxa, diverge there is long-lasting gene exchange resulting in mosaic genomes consisting of some shared cassettes and others that are not shared. Which portions of the genomes introgress depends on selection, demography and the genotypes involved in the various stages of hybridization (Arnold, 1997, 2006). Overall then, evolution within the primates, as in numerous other clades, argues against the Darwinian and Neo-Darwinian assumption that natural hybridization is trivial. Instead, the data from lemurs to humans reflects the simultaneous processes of divergence and reticulation.

We feel that genome projects for primate taxa hold the promise of strong inferences concerning the evolutionary role that reticulation has played in various clades. Though the number of sequenced genomes will be limited, the possibility for extrapolation between taxonomic groups of primates - in light of estimated divergence times, geographical distributions, effective population sizes and the geographic opportunity to hybridize - will be facilitated. Further, there is a need for a tremendous emphasis to be placed on gathering more complete genotype data from many individuals from multiple, natural populations. Only with a range of genomic and population genetic studies can we hope, as in other better-surveyed species complexes, to be able to discern the various evolutionary processes including reticulation.

Finally, we would suggest that a recognition of the descriptive and predictive power of the web-of-life metaphor (Arnold and Larson, 2004; Arnold, 2006) will greatly aid in one of the most important areas of primate biology, that of conservation. An understanding that a cycle of divergence and hybridization characterizes the evolutionary process should alleviate the concern that hybridization somehow indicates a lesser unit (i.e. not a species) and thus negates the urgency for conservation. Instead, the reality of a reticulate rather than purely divergent evolutionary pattern indicates that genetic enrichment through introgression and hybrid speciation is the natural outcome of evolution. Such an outlook is reflected in the following quote from Hey et al. (2003): "In recent decades, this simple realization of the fundamental insufficiency of taxa as the focus of conservation efforts has shifted those efforts towards research on how best to conserve evolving populations." 


\section{Acknowledgments}

A portion of this review was completed while MLA was a Visiting Professor supported by the Universität Konstanz. MLA was also supported by National Science Foundation Grants DEB-0074159 and DEB0345123 and AM by Grants of the Deutsche Forschungsgemeinschaft. We thank S. Cornman, J. RossIbarra, N. Martin and W. Salzburger for helpful comments on an earlier version of the manuscript.

\section{References}

Alberts, S.C., Altmann, J., 2001. Immigration and hybridization patterns of yellow and anubis baboons in and around Amboseli, Kenya. Am. J. Primatol. 53, 139-154.

Arnold, M.L., 1993. Iris nelsonii: origin and genetic composition of a homoploid hybrid species. Am. J. Bot. 80, 577-583.

Arnold, M.L., 1997. Natural Hybridization and Evolution. Oxford Series in Ecology and Evolution. Oxford University Press, Oxford.

Arnold, M.L., 2004a. Natural hybridization and the evolution of domesticated, pest, and disease organisms. Mol. Ecol. 13, 997-1007.

Arnold, M.L., 2004b. Transfer and origin of adaptations through natural hybridization: were Anderson and Stebbins right? Plant Cell 16, 1-9.

Arnold, M.L., 2006. Evolution Through Genetic Exchange. Oxford University Press, Oxford.

Arnold, M.L., Larson, E.J., 2004. Evolution's new look. The Wilson Quarterly Autumn, 60-72.

Avise, J.C., 1994. Molecular Markers, Natural History and Evolution. Chapman \& Hall, New York.

Avise, J.C., 2000. Phylogeography-The History and Formation of Species. Harvard University Press, Cambridge, MA.

Avise, J.C., Neigel, J.E., Arnold, J., 1984. Demographic influences on mitochondrial DNA lineage survivorship in animal populations. J. Mol. Evol. 20, 99-105.

Burke, J.M., Arnold, M.L., 2001. Genetics and the fitness of hybrids. Annu. Rev. Genet. 35, 31-52.

Bynum, N., 2002. Morphological variation within a macaque hybrid zone. Am. J. Phys. Anthropol. 118, 45-49.

Bynum, E.L., Bynum, D.Z., Supriatna, J., 1997. Confirmation and location of the hybrid zone between wild populations of Macaca tonkeana and Macaca hecki in central Sulawesi, Indonesia. Am. J. Primatol. 43, 181-209.

Caramelli, D., Lalueza-Fox, C., Vernesi, C., Lari, M., Casoli, A., Mallegni, F., Chiarelli, B., Dupanloup, I., Bertranpetit, J., Barbujani, G., Bertorelle, G., 2003. Evidence for a genetic discontinuity between Neandertals and 24,000-yearold anatomically modern humans. Proc. Natl. Acad. Sci. USA 100, 6593-6597.

Collins, A.C., Dubach, J.M., 2000. Biogeographic and ecological forces responsible for speciation in Ateles. Int. J. Primat. 21, 421-444.

Collins, A.C., Dubach, J.M., 2001. Nuclear DNA variation in spider monkeys (Ateles). Mol. Phyl. Evol. 19, 67-75.
Cortés-Ortiz, L., Bermingham, E., Rico, C., Rodríguez-Luna, E., Sampaio, I., Ruiz-García, M., 2003. Molecular systematics and biogeography of the Neotropical monkey genus, Alouatta. Mol. Phyl. Evol. 26, 64-81.

Cropp, S.J., Larson, A., Cheverud, J.M., 1999. Historical biogeography of tamarins, genus Saguinus: the molecular phylogenetic evidence. Am. J. Phys. Anthropol. 108, 65-89.

Darwin, C., 1859. On the Origin of Species by Means of Natural Selection or the Preservation of Favoured Races in the Struggle for Life. John Murray, London.

Deinard, A., Kidd, K., 1999. Evolution of a HOXB6 intergenic region within the great apes and humans. J. Hum. Evol. 36, 687-703.

DeMarais, B.D., Dowling, T.E., Douglas, M.E., Minckley, W.L., Marsh, P.C., 1992. Origin of Gila seminuda (Teleostei: Cyprinidae) through introgressive hybridization: implications for evolution and conservation. Proc. Natl. Acad. Sci. USA 89, 2747-2751.

Detwiler, K.M., Burrell, A.S., Jolly, C.J., 2005. Conservation implications of hybridization in African cercopithecine monkeys. Int. J. Primat. 26, 661-684.

Dirks, W., Reid, D.J., Jolly, C.J., Phillips-Conroy, J.E., Brett, F.L., 2002. Out of the mouths of baboons: stress, life history, and dental development in the Awash National Park hybrid zone, Ethiopia. Am. J. Phys. Anthropol. 118, 239-252.

Disotell, T.R., 1994. Generic level relationships of the Papionini (Cercopithecoidea). Am. J. Phys. Anthropol. 94, 47-57.

Dobzhansky, Th., 1937. Genetics and the Origin of Species. Columbia University Press, New York.

Dowling, T.E., DeMarais, B.D., 1993. Evolutionary significance of introgressive hybridization in cyprinid fishes. Nature 362, 444-446.

Duarte, C., Maurício, J., Pettitt, P.B., Souto, P., Trinkaus, E., van der Plicht, H., Zilhão, J., 1999. The early upper Paleolithic human skeleton from the Abrigo do Lagar Velho (Portugal) and modern human emergence in Iberia. Proc. Natl. Acad. Sci. USA 96, 7604-7609.

Evans, B.J., Morales, J.C., Supriatna, J., Melnick, D.J., 1999. Origin of the Sulawesi macaques (Cercopithecidae: Macaca) as suggested by mitochondrial DNA phylogeny. Biol. J. Linn. Soc. 66, 539-560.

Evans, B.J., Supriatna, J., Melnick, D.J., 2001. Hybridization and population genetics of two macaque species in Sulawesi, Indonesia. Evolution 55, 1686-1702.

Evans, B.J., Supriatna, J., Andayani, N., Melnick, D.J., 2003. Diversification of Sulawesi macaque monkeys: decoupled evolution of mitochondrial and autosomal DNA. Evolution 57, 1931-1946.

Fitzpatrick, B.M., 2004. Rates of evolution of hybrid inviability in birds and mammals. Evolution 58, 1865-1870.

Garrigan, D., Mobasher, Z., Severson, T., Wilder, J.A., Hammer, M.F., 2005. Evidence for archaic Asian ancestry on the human $\mathrm{X}$ chromosome. Mol. Biol. Evol. 22, 189-192.

Goodfriend, G.A., Gould, S.J., 1996. Paleontology and chronology of two evolutionary transitions by hybridiza- 
tion in the Bahamian land snail Cerion. Science 274, 1894-1897.

Grant, P.R., Grant, B.R., 2002. Unpredictable evolution in a 30-year study of Darwin's finches. Science 296, 707-711.

Harris, E.E., Disotell, T.R., 1998. Nuclear gene trees and the phylogenetic relationships of the mangabeys (Primates: Papionini). Mol. Biol. Evol. 15, 892-900.

Harrison, R.G., 1986. Pattern and process in a narrow hybrid zone. Heredity 56, 337-349.

Harrison, R.G., 1990. Hybrid zones: windows on evolutionary process. Oxford Surveys Evol. Biol. 7, 69-128.

Hawks, J.D., Wolpoff, M.H., 2001. The accretion model of Neandertal evolution. Evolution 55, 1474-1485.

Hayasaka, K., Fujii, K., Horai, S., 1996. Molecular phylogeny of macaques: implications of nucleotide sequences from an 896-base pair region of mitochondrial DNA. Mol. Biol. Evol. 13, 1044-1053.

Hayashi, S., Hayasaka, K., Takenaka, O., Horai, S., 1995. Molecular phylogeny of gibbons inferred from mitochondrial DNA sequences: preliminary report. J. Mol. Evol. 41, 359-365.

Hey, J., Waples, R.S., Arnold, M.L., Butlin, R.K., Harrison, R.G., 2003. Understanding and confronting species uncertainty in biology and conservation. Trends Ecol. Evol. 18, 597-603.

Hofmann, W., 1991. The late-glacial/Holocene Bosmina (Eubosmina) fauna of Lake Constance (Untersee) (F.R.G.): traces of introgressive hybridization. Hydrobiologia 225, 81-85.

Holliday, T.W., 2003. Species concepts, reticulation, and human evolution. Curr. Anthrop. 44, 653-673.

Jolly, C.J., 2001. A proper study for mankind: analogies from the papionin monkeys and their implications for human evolution. Yearbook Phys. Anthrop. 44, 177-204.

Jolly, C.J., Wooley-Barker, T., Beyene, S., Disotell, T.R., Phillips-Conroy, J.E., 1997. Intergeneric hybrid baboons. Int. J. Primat. 18, 597-627.

Kaessmann, H., Wiebe, V., Pääbo, S., 1999. Extensive nuclear DNA sequence diversity among chimpanzees. Science 286 , 1159-1162.

Kawamoto, Y., 2005. NRAMP1 polymorphism in a hybrid population between Japanese and Taiwanese macaques in Wakayama, Japan. Primates 46, 203-206.

Key, K.H.L., 1968. The concept of stasipatric speciation. Syst. Zool. 17, 14-22.

Krings, M., Stone, A., Schmitz, R.W., Krainitzki, H., Stoneking, M., Pääbo, S., 1997. Neandertal DNA sequences and the origin of modern humans. Cell 90, 19-30.

Mallet, J., 2005. Hybridization as an invasion of the genome. Trends Ecol. Evol. 20, 229-237.

Marchant, A.D., Arnold, M.L., Wilkinson, P., 1988. Gene flow across a chromosomal tension zone. I. Relicts of ancient hybridization. Heredity 61, 321-328.

Marroig, G., Cropp, S., Cheverud, J.M., 2004. Systematics and evolution of the jacchus group of marmosets (Platyrrhini). Am. J. Phys. Anthropol. 123, 11-22.

Mayor, M.I., Sommer, J.A., Houck, M.L., Zaonarivelo, J.R., Wright, P.C., Ingram, C., Engel, S.R., Louis Jr., E.E., 2004. Specific status of Propithecus spp. Int. J. Primat. 25, 875-900.
Mayr, E., 1942. Systematics and the Origin of Species. Columbia University Press, New York.

Mayr, E., 1963. Animal Species and Evolution. Belknap Press, Cambridge, MA.

Messier, W., Stewart, C.-B., 1997. Episodic adaptive evolution of primate lysozymes. Nature 385, 151-154.

Morales, J.C., Melnick, D.J., 1998. Phylogenetic relationships of the macaques (Cercopithecidae: Macaca), as revealed by high resolution restriction site mapping of mitochondrial ribosomal genes. J. Hum. Evol. 34, 1-23.

Morin, P.A., Moore, J.J., Chakraborty, R., Jin, L., Goodall, J., Woodruff, D.S., 1994. Kin selection, social structure, gene flow, and the evolution of chimpanzees. Science 265, 1193-1201.

Muir, C.C., Galdikas, B.M.F., Beckenbach, A.T., 2000. mtDNA sequence diversity of orangutans from the islands of Borneo and Sumatra. J. Mol. Evol. 51, 471-480.

Myers, R.H., Shafer, D.A., 1979. Hybrid ape offspring of a mating of gibbon and siamang. Science 205, 308-310.

Navarro, A., Barton, N.H., 2003. Chromosomal speciation and molecular divergence - accelerated evolution in rearranged chromosomes. Science 300, 321-324.

Newman, T.K., Jolly, C.J., Rogers, J., 2004. Mitochondrial phylogeny and systematics of baboons (Papio). Am. J. Phys. Anthropol. 124, 17-27.

Noda, R., Kim, C.G., Takenaka, O., Ferrell, R.E., Tanoue, T., Hayasaka, I., Ueda, S., Ishida, T., Saitou, N., 2001. Mitochondrial 16S rRNA sequence diversity of hominoids. J. Hered. 92, 490-496.

O’hUigin, C., Satta, Y., Takahata, N., Klein, J., 2002. Contribution of homoplasy and of ancestral polymorphisms to the evolution of genes in anthropoid primates. Mol. Biol. Evol. 19, 1501-1513.

Osada, N., Wu, C.-I., 2005. Inferring the mode of speciation from genomic data: a study of the great apes. Genetics 169 , 259-264.

Ovchinnikov, I.V., Götherström, A., Romanova, G.P., Kharitonov, V.M., Lidén, K., Goodwin, W., 2000. Molecular analysis of Neanderthal DNA from the northern Caucasus. Nature 404, 490-493.

Pääbo, S., 2003. The mosaic that is our genome. Nature 421, 409-412.

Pastorini, J., Forstner, M.R.J., Martin, R.D., 2001. Phylogenetic history of sifacas (Propithecus: Lemuriformes) derived from mtDNA sequences. Am. J. Primatol. 53, 1-17.

Pastorini, J., Thalmann, U., Martin, R.D., 2003. A molecular approach to comparative phylogeography of extant Malagasy lemurs. Proc. Natl. Acad. Sci. USA 100, 5879-5884.

Pesole, G., Sbisá, E., Preparata, G., Saccone, C., 1992. The evolution of the mitochondrial D-loop region and the origin of modern man. Mol. Biol. Evol. 9, 587-598.

Prager, E.M., Wilson, A.C., 1975. Slow evolutionary loss of the potential for interspecific hybridization in birds: a manifestation of slow regulatory evolution. Proc. Natl. Acad. Sci. USA 72, 200-204.

Richard, F., Lombard, M., Dutrillaux, B., 2000. Phylogenetic origin of human chromosomes 7, 16, and 19 and their homologs in placental mammals. Genet. Res. 10, 644-651.

Rieseberg, L.H., Livingstone, K., 2003. Chromosomal speciation in primates. Science 300, 267-268. 
Rieseberg, L.H., Carter, R., Zona, S., 1990. Molecular tests of the hypothesized hybrid origin of two diploid Helianthus species (Asteraceae). Evolution 44, 1498-1511.

Roos, C., Geissmann, T., 2001. Molecular phylogeny of the major hylobatid divisions. Mol. Phyl. Evol. 19, 486-494.

Rosenblum, L.L., Supriatna, J., Hasan, M.N., Melnick, D.J., 1997. High mitochondrial DNA diversity with little structure within and among leaf monkey populations (Trachypithecus auratus and Trachypithecus cristatus). Int. J. Primat. 18, 1005-1028.

Salem, A.-H., Ray, D.A., Xing, J., Callinan, P.A., Myers, J.S., Hedges, D.J., Garber, R.K., Witherspoon, D.J., Jorde, L.B., Batzer, M.A., 2003. Alu elements and hominid phylogenetics. Proc. Natl. Acad. Sci. USA 100, 12787-12791.

Salzburger, W., Baric, S., Sturmbauer, C., 2002. Speciation via introgressive hybridization in East African cichlids? Mol. Ecol. 11, 619-625.

Schillaci, M.A., Froehlich, J.W., 2001. Nonhuman primate hybridization and the taxonomic status of Neanderthals. Am. J. Phys. Anthropol. 115, 157-166.

Seehausen, O., 2004. Hybridization and adaptive radiation. Trends Ecol. Evol. 19, 198-207.

Shotake, T., 1981. Population genetical study of natural hybridization between Papio anubis and P. hamadryas. Primates 22, 285-308.

Shotake, T., Nozawa, K., Tanabe, Y., 1977. Blood protein variations in baboons. I. Gene exchange and genetic distance between Papio anubis, Papio hamadryas and their hybrid. Jpn. J. Genet. 52, 223-237.

Smith, D.G., McDonough, J., 2005. Mitochondrial DNA variation in Chinese and Indian rhesus macaques (Macaca mulatta). Am. J. Primatol. 65, 1-25.

Stone, A.C., Griffiths, R.C., Zegura, S.L., Hammer, M.F., 2002. High levels of Y-chromosome nucleotide diversity in the genus Pan. Proc. Natl. Acad. Sci. USA 99, 43-48.

Szmulewicz, M.N., Andino, L.M., Reategui, E.P., WooleyBarker, T., Jolly, C.J., Disotell, T.R., Herrera, R.J., 1999. An Alu insertion polymorphism in a baboon hybrid zone. Am. J. Phys. Anthropol. 109, 1-8.

Tagliaro, C.H., Schneider, M.P.C., Schneider, H., Sampaio, I.C., Stanhope, M.J., 1997. Marmoset phylogenetics, conservation perspectives, and evolution of the mtDNA control region. Mol. Biol. Evol. 14, 674-684.

Takahashi, K., Nishida, M., Yuma, M., Okada, N., 2001. Retroposition of the AFC family of SINEs (short interspersed repetitive elements) before and during the adaptive radiation of cichlid fishes in Lake Malawi and related inferences about phylogeny. J. Mol. Evol. 53, 496-507.
Takahata, N., Lee, S.-H., Satta, Y., 2001. Testing multiregionality of modern human origins. Mol. Biol. Evol. 18, 172-183.

Tattersall, I., Schwartz, J.H., 1999. Hominids and hybrids: the place of Neanderthals in human evolution. Proc. Natl. Acad. Sci. USA 96, 7117-7119.

Templeton, A.R., 2002. Out of Africa again and again. Nature 416, 45-51.

Templeton, A.R., 2005. Haplotype trees and modern human origins. Yearbook Phys. Anthropol. 48, 33-59.

Tosi, A.J., Morales, J.C., Melnick, D.J., 2000. Comparison of Y chromosome and mtDNA phylogenies leads to unique inferences of macaque evolutionary history. Mol. Phyl. Evol. 17, 133-144.

Tosi, A.J., Morales, J.C., Melnick, D.J., 2002. Y-chromosome and mitochondrial markers in Macaca fascicularis indicate introgression with Indochinese M. mulatta and a biogeographic barrier in the Isthmus of Kra. Int. J. Primat. 23, 161-178.

Tosi, A.J., Morales, J.C., Melnick, D.J., 2003. Paternal, maternal, and biparental molecular markers provide unique windows onto the evolutionary history of macaque monkeys. Evolution 57, 1419-1435.

Warren, K.S., Verschoor, E.J., Langenhuijzen, S., Heriyanto, Swan, R.A., Vigilant, L., Heeney, J.H., 2001. Speciation and intrasubspecific variation of Bornean orangutans, Pongo pygmaeus pygmaeus. Mol. Biol. Evol. 18, $472-480$.

Watanabe, H., Fujiyama, A., Hattori, M., Taylor, T.D., Toyoda, A., et al., 2004. DNA sequence and comparative analysis of chimpanzee chromosome 22. Nature 429, 382-388.

Wolpoff, M.H., Hawks, J., Frayer, D.W., Hunley, K., 2001. Modern human ancestry at the peripheries: a test of the replacement theory. Science 291, 293-297.

Won, Y.-J., Hey, J., 2005. Divergence population genetics of chimpanzees. Mol. Biol. Evol. 22, 297-307.

Wyner, Y.M., Johnson, S.E., Stumpf, R.M., DeSalle, R., 2002. Genetic assessment of a White-Collared X Red-Fronted lemur hybrid zone at Andringitra, Madagascar. Am. J. Primatol. 67, 51-66.

Xu, X., Arnason, U., 1996. The mitochondrial DNA molecule of Sumatran orangutan and a molecular proposal for two (Bornean and Sumatran) species of orangutan. J. Mol. Evol. 43, 431-437.

Zhi, L., Karesh, W.B., Janczewski, D.N., Frazier-Taylor, H., Sajuthi, D., Gombek, F., Andau, M., Martenson, J.S., O’Brien, S.J., 1996. Genomic differentiation among natural populations of orangutan (Pongo pygmaeus). Curr. Biol. 6, 1326-1336. 